Piloto et al., 2018

Volume 4 Issue 3, pp.104-124

Date of Publication: 20th November, 2018

DOI-https://dx.doi.org/10.20319/mijst.2018.43.104124

This paper can be cited as: Piloto, P. A. G., Khetata, M. S., EGavilán, A. B. R. (2018). Loadbearng

Capactty of LSF Walls under Fire Exposure. MATTER: International Journal of Science and Technology, 4(3), 104-124.

This work is licensed under the Creative Commons Attribution-Non Commercial 4.0 International License. To view a copy of this license, visit http://creativecommons.org/licenses/by-nc/4.0/ or send a letter to Creative Commons, PO Box 1866, Mountain View, CA 94042, USA.

\title{
LOADBEARING CAPACITY OF LSF WALLS UNDER FIRE EXPOSURE
}

\author{
Paulo A. G. Piloto \\ ppiloto@ipb.pt \\ Mohamed S. Khetata \\ University of Salamanca, Zamora, Spain \\ khetatamohamedseddik@gmail.com
}

LAETA-INEGI, Polytechnic Institute of Bragança, Bragança, Portugal

Ana B. R. Gavilán

Dep. of Mech. Engineering, University of Salamanca, Zamora, Spain

aramos@usal.es

\begin{abstract}
Light steel frame (LSF) (LSF) and prefabricated panels are widely used in loadbearing walls, with direct application to steel framed buildings. These walls are made with steel cold formed sections (studs and tracks) using gypsum plasterboard and other material layers attached to the flanges and sometimes insulation material in the cavities. The fire resistance is usually provided by one or more layer of materials and or by the cavity insulation. This investigation evaluates the fire resistance of the loadbearing walls, from the point of view of insulation (I) and loadbearing capacity (R). Experimental resultsobtained from partition walls were used into the numerical model to accurately preview the cracking, falling off and the ignition of combustible material. The numerical model was validated under the same fire conditions. The loadbearing capacity is determined usingthis hybrid model. This model is able to predict an accurate fire resistance for any load level, taking into account the brittle behaviour of gypsum panels and the
\end{abstract}


ignition of combustible materials. The loadbearing decreases with the increase of the load level. A new formula is presented to determine the critical average temperature of the LSF.

\section{Keywords}

LSF Walls, Fire Resistance, Numerical Simulation, Experimental Tests

\section{Introduction}

Loadbearing walls made with light steel frame (LSF) and prefabricated panels are widely used in building industry, with wide application to building structures. The fire resistance is normally determined by experimental tests according to standards, without the existence of any prescription or performed base code to design this building element under fire conditions. The design of this building element presents cold formed steel profiles, dully protected with plasterboards or any composite material to slow down the effect of the fire. The plasterboards are normally used as a simple protection material and may also be combined with other materials, as a composite solution. The steel structure allows the formation of cavities between the plates or composite panels, which can be filled with insulation materials. Special attention should be given to the assembly of the different elements of the structure, in particular the joints between the elements, installation of windows and service components.

Different studies have been developed to test the efficiency of the plasterboards, the efficiency of the insulation materials, the efficiency of the LSF, among other design parameters. One of the first experimental fire test on LSF walls was developed in 1973 by B. C. Son and H. Shoub(Son \& Shoub, 1973), who explained in detail two fire-endurance tests on double-wall assemblies. Authors concluded from the temperature data of the second test a much slower temperature rise in the fire-exposed gypsum board due to the existence of a thicker plate. Kenneth J. Schwartz and T. T. Lie in 1985 (Schwartz \& Lie, 1985), studied the effect of the heat transmission to prevent ignition of the materials in contact with the unexposed side of the partition walls, throughout experimental tests to evaluate the temperature criteria for the unexposed side of the standard ASTM E119. J T HansGerlich in 1995(J. T. H. Gerlich, 1995) and later J. T. Gerlich el al in 1996 (J. T. Gerlich, Collier, \& Buchanan, 1996) investigated the parameters which affect the performance of loadbearing LSF drywall systems exposed to fire. Sultan, M.A (Sultan, 1996) in 1996 summarized the results obtained from a numerical simulation and experimental tests for predicting the fire resistance of non-insulated and unloaded steel-stud wall assemblies. In 1999, FaridAlfawakhiri et al (Alfawakhiri, Sultan, \& MacKinnon, 
1999)made a literature review about LSF loadbearing walls under fire. Previous experimental and analytical studies used for fire rating are presented and the temperature dependent materials properties are also discussed. Other important considerations regarding failure of gypsum boards are presented, in particular the effect of the screw spacing, orientation of gypsum board joints, and stud spacing, which can have a very strong effect of the fire performance. Later on, the same authors(Alfawakhiri \& Sultan, 2000) presented a comparison study between fire tests and numerical simulations. The model demonstrates how different heating regimes applied in cold formed steel studs cause different structural failure modes. An experimental investigation was also developed by Y. Sakumoto el al. in 2003 (Sakumoto, Hirakawa, Masuda, \& Nakamura, 2003) to evaluate the fire resistance of walls using galvanized LSF. Authors concluded that protection layers of plywood, gypsum boards, and other materials, depend mainly on the thermal shielding performance of the attached gypsum boards. In 2010,PrakashKolarkar(Kolarkar, 2010) evaluate the structural and thermal performance of LSF wall systems under fire conditions. This work improved the knowledge about the fire behaviour of both loadbearing and non-loadbearing walls, developed a new concept for wall system and presented a reliable method to predict the fire rating. In 2013, Shahbazian et al (Shahbazian \& Wang, 2013) proposed a simple method (one-dimensional heat flow analysis) to calculate the temperature field in the steel section when the wall panel is exposed to fire. The results agree with the results obtained from the bidimensional analysis using ABAQUS. In the same year, PoologanathanKeerthan and Mahen Mahendran (Keerthan \& Mahendran, 2013) developed a numerical study with SAFIR to determine the thermal performance of the composite panels, made by two plasterboards with an insulation layer between them, proposing new simple formulas to estimate the temperature evolution in the unexposed side. In 2014, PoologanathanKeerthan and Mahen Mahendran [24] presented a comparison between numerical results and experimental results obtained for the thermal performance of loadbearing cold-formed steel walls under fire conditions, showing good agreement between them. In 2016 SivakumarKesawan and Mahen Mahendran (Sivakumar Kesawan and Mahen Mahendran, 2016) developed accurate finite element models with SAFIR, using apparent thermal properties for the gypsum plasterboard, involved in the fire simulation of loadbearing walls made with hollow flange channel section studs. The numerical results were validated with five full scale experimental tests. The models predicted very well the temperature in the gypsum and in the steel frame. In 2017 SivakumarKesawan and Mahen Mahendran (Kesawan \& Mahendran, 2017) presented a numerical study about the structural fire 
performance of LSF walls under fire conditions. Authors validated the numerical models with previous 5 fire experiments (Kesawan \& Mahendran, 2015), where they found the superior behaviour of welded hollow flange channel (HFC) cross section type in the fire resistance of LSF walls.

The fire performance on LSF walls is also being developed at the Polytechnic Institute of Bragança (Portugal), with the aim of developing accurate numerical models based on the thermal analysis with fluid structure interaction (Piloto, Khetata, \& Gavilán., 2017), validate the numerical models with experimental tests developed elsewhere (Khetata et al., 2017), analysing the fire performance of LSF using simplified one dimensional heat flow (Piloto, Khetata, \& Gavilán, 2017) and presenting a sequential numerical model to study the fire resistance of LSF walls made with composite panels (Piloto, 2018). This manuscript presents some experimental tests developed for non-loadbearing walls with empty cavity, also presents the three dimensional validation model and a parametric analysis able to predict the fire resistance of LSF loadbearing walls, when using the same geometry and materials of the partition walls.

\section{Experimental tests on non-loadbearing walls}

The main objective is to determine the fire resistance (I) of different composite solutions used on LSF walls. The fire resistance (I) is the ability of the element to withstand exposure to fire only on one side, without significant heat transfer from the exposed side to the unexposed side. The heat transfer should be limited to avoid that the unexposed surface or any material close to that surface is ignited. The classification (I) of a wall should be attributed based on the shortest time for which the criteria of maximum or average temperature increase are satisfied in any discrete area. The fire performance level used to define the insulation shall be calculated on the basis of the increase in average temperature on the unexposed side, limited to $140^{\circ} \mathrm{C}$ above the initial average temperature, or, based on the increase of the maximum temperature in any location, limited to $180^{\circ} \mathrm{C}$ above the initial average temperature.

The partition walls under analysis are made of 5 vertical studs and 2 tracks, being this investigation part of a larger study of materials for LSF walls. The 4 specimens presented herein

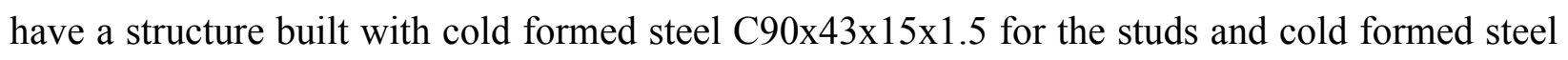
U93 $43 \times 1.5$ for the tracks. Both profiles belong to steel grade S280GD, which means that the value of the $0.2 \%$ of proof strength is $280 \mathrm{GPa}$. The geometry and dimensions are representative of a real structure, but adapted to the dimensions of the fire resistance furnace from the 
Polytechnic Institute of Bragança. Figure 1 shows the dimensions of the wall under investigation with a cavity thickness of $90 \mathrm{~mm}$, the insertion of the wall into the testing frame and the positions of the main disc thermocouples, applied in the unexposed side.

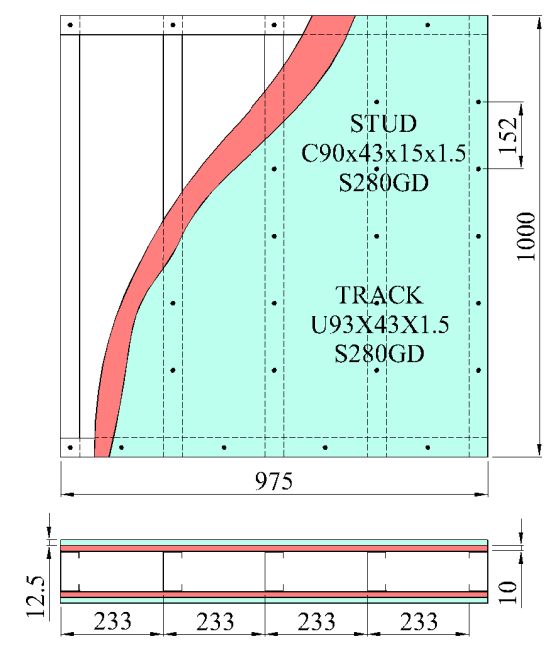

a) LSF specimen with composite panels.

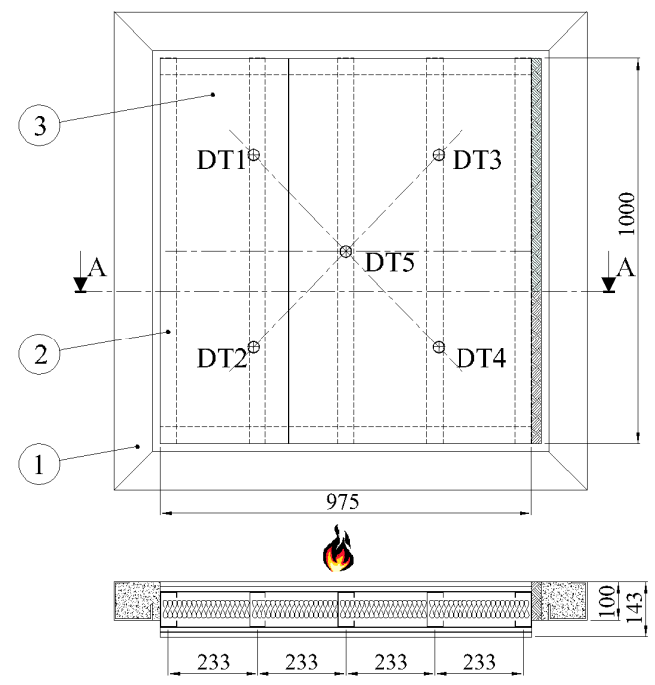

b) LSF wall specimen fixed in the testing frame (1), with studs (2) and layer plates (3) and tracks, along with the main disc thermocouples (DT).

Figure 1: LSF walls under investigation

Self-drilling screws of diameter 4.2 and $4.8 \mathrm{~mm}$ and lengths of 19, 38 and $50 \mathrm{~mm}$ spaced every $152 \mathrm{~mm}$ were used. The LSF was fixed to the test frame around 3 edges (left, bottom and top) allowing a free edge, properly filled with ceramic fibre (right side with $25 \mathrm{~mm}$ ). All the edges of the wall boundary were filled with gypsum. The dimensions of the specimens were adjusted to the dimensions of the furnace and do not comply with the standard dimensions, normally used for testing EN 1364-1 (CEN- European Committee for Standardization, 2015). All the other condition specified in this standard were met as well as all the general requirements for standard fire tests EN1363-1 (CEN- European Committee for Standardization, 2012).

Four specimens were tested under fire conditions to evaluate the insulation effect of the layer plates. Two different types of plasterboards were used (Gypsum 1 is fired proof with two layers of multilayer paper, with high purity natural gypsum inner core reinforced with fiberglass filaments and duly added with thermo-expandable minerals with density of $770 \mathrm{~kg} / \mathrm{m} 3$; and gypsum 2 is normal gypsum, made with laminated gypsum board consisting of two layers of multilayer paper, with high purity natural gypsum inner core reinforced with fiberglass filaments and with density of $760 \mathrm{~kg} / \mathrm{m} 3$ ). 
The fire resistance was determined in complete minutes for all the specimens, using the criterion for the maximum temperature (using DT measurements), average temperature (using DT measurement) and average temperature (using Infra-Red measurement). All the specimens have the same LSF structure, see Table 1. Specimen 01 is made with a single layer gypsum 1 , specimen 02 is made with double layer gypsum 1, both with $12.5 \mathrm{~mm}$. Specimen 04 is made with a composite solution with $10 \mathrm{~mm}$ of cork and $12.5 \mathrm{~mm}$ of gypsum 2 and specimen 07 is also a composite solution made with $10 \mathrm{~mm}$ OSB wood and $12.5 \mathrm{~mm}$ gypsum 2.

Table 1: Specimens characteristics.

\begin{tabular}{|l|l|l|}
\hline Specimen ID & $\begin{array}{l}\text { Material / thickness [mm] } \\
\text { Layer 1 }\end{array}$ & $\begin{array}{l}\text { Material / thickness [mm] } \\
\text { Layer 2 }\end{array}$ \\
\hline 01 & Gypsum 1/ 12.5 & - \\
\hline 02 & Gypsum 1/ 12.5 & Gypsum /12.5 \\
\hline 04 & Cork / 10 & Gypsum 2 / 12.5 \\
\hline 07 & Wood OSB / 10 & Gypsum 2 / 12.5 \\
\hline
\end{tabular}

Different thermocouples were used in accordance to standard testing conditions. Type K thermocouples were used in different formats for temperature measurement: copper disk with plasterboard protection - DTi for unexposed surface temperature measurement; welded joint applied on cold formed steel profiles - WTi for temperature measurement in 3 different regions (hot flange, web and cold flange); PTi plate for measuring the temperature developed in the 4 cavities and also the ambient temperature (200 $\mathrm{mm}$ away from the unexposed surface); sheath thermocouples - BTi for temperature measurement on the exposed surface. The number of thermocouples depends on the specimen to be tested, see Figure 2 for all the thermocouples used in the tested specimens.

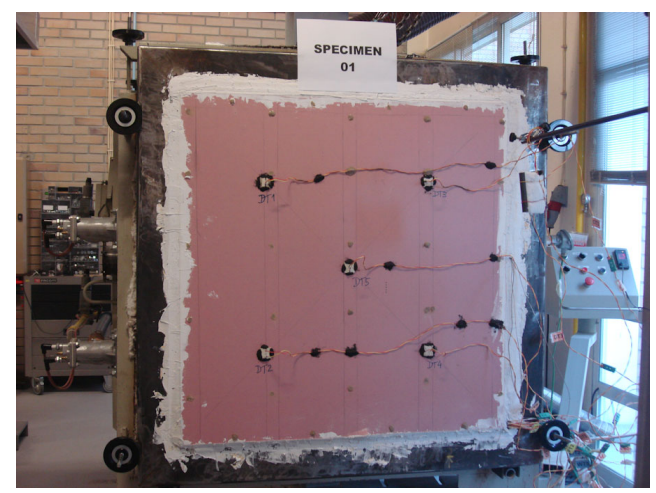

a) Specimen 01 .

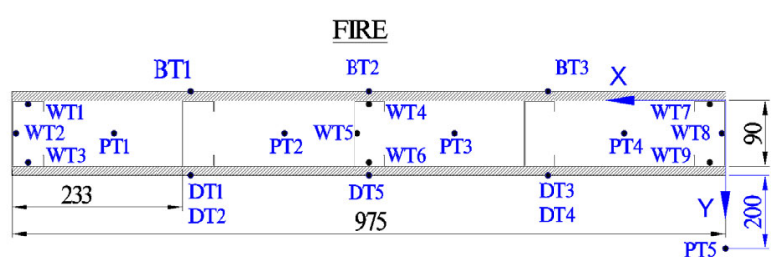

b) Thermocouples used in specimen 01 . 


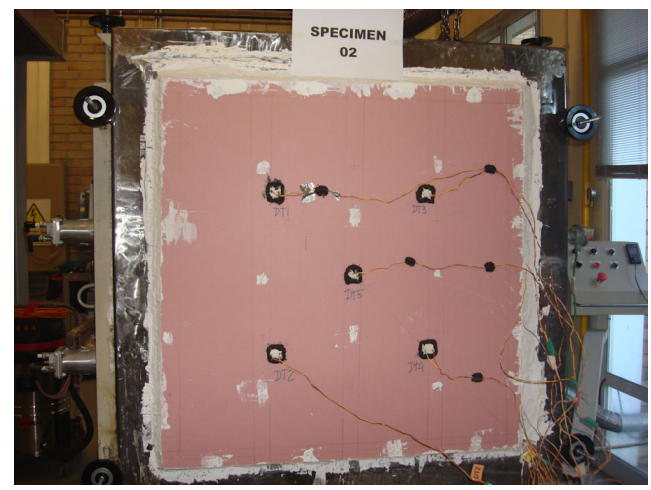

c) Specimen 02 .

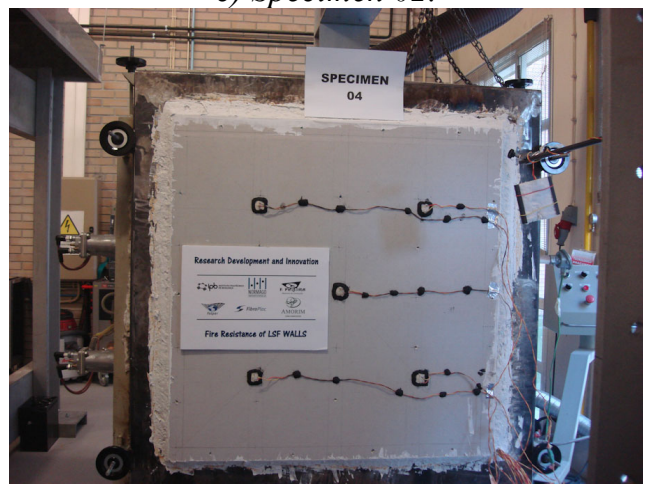

e) Specimen 04.

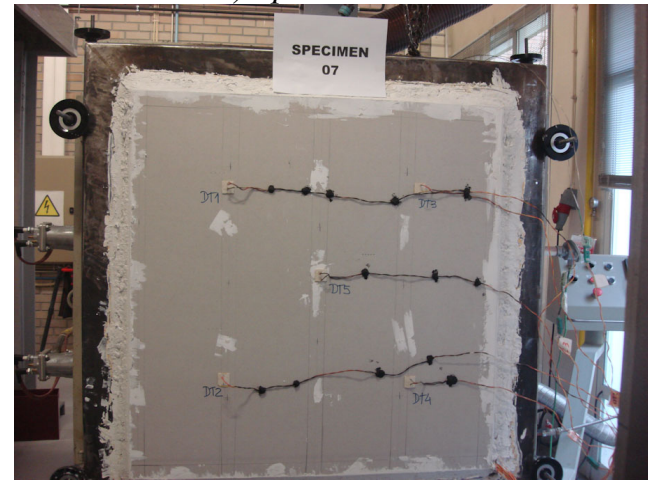

g) Specimen 07.

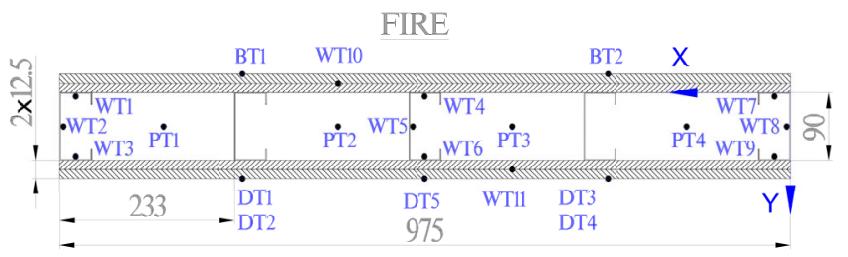

d) Thermocouples used in specimen 02 .

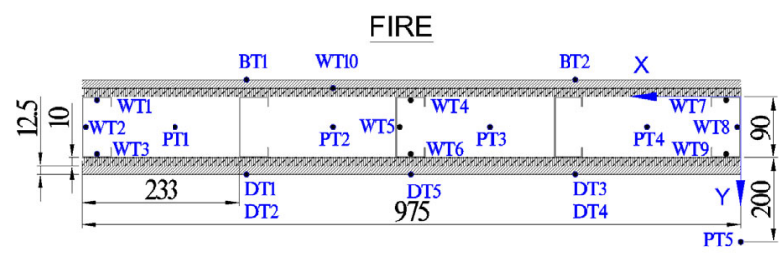

f) Thermocouples used in specimen 04 .

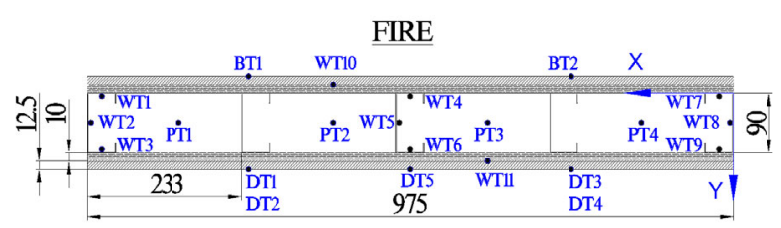

h) Thermocouples used in specimen 07.

Figure 2: Specimens and sensors for temperature measurement

All the specimens were submitted to standard fire ISO834 (International Organization for Standardization, 1999). Different failure modes were achieved due to local and global buckling modes and identified as the ultimate limit state of the frame, see Figure 3. For some specimens (specimen 04 and specimen 07), the furnace temperature presented two moments with some instability, related to the ignition of the combustible material (cork and OSB). The cork layer located on the exposed side ignited at minute 20, while the cork layer on the unexposed side ignited at minute 36. Both plates made of OSB layer start ignition for the same time instants. All other specimens kept the real furnace temperature close to the ISO834. The average temperature 
is depicted for each specimen, using the results of individual measurements, to represent the evolution on the hot flange (HF), web (WEB) and cold flange (CF). The unexposed temperature was measured with standalone disc thermocouples UNEXP (DT) and with a FLIR infrared thermal camera, UNEXP (IR). Special measurements were also developed for some specimens, such as: the average temperature of the cavity (CAV), the room temperature (AMB) and the interface temperature between the composite layers (PBi-PBj).

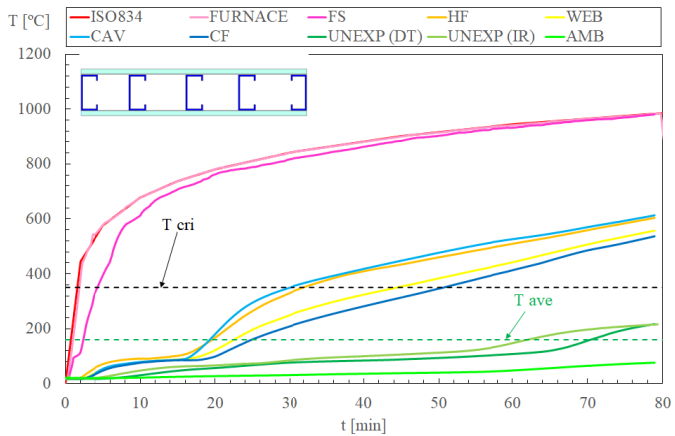

a) average temperature results for specimen 01 .

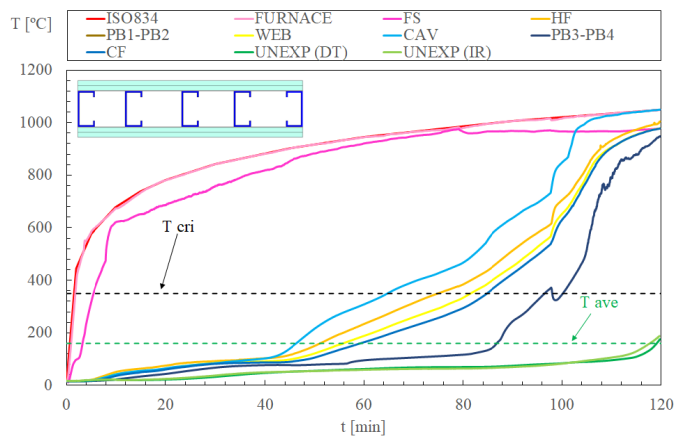

c) average temperature results for specimen 02 .

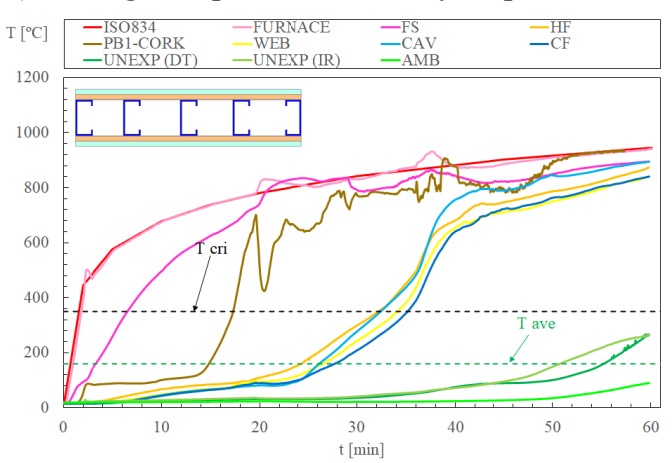

g) average temperature results for specimen 04 .

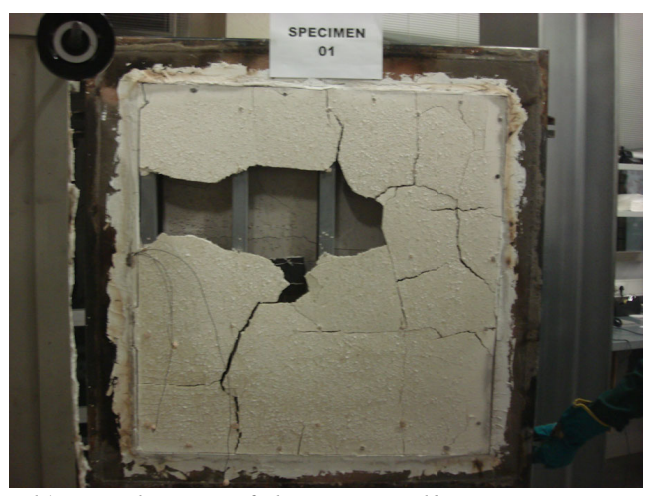

b) Final state of the LSF wall specimen 01.

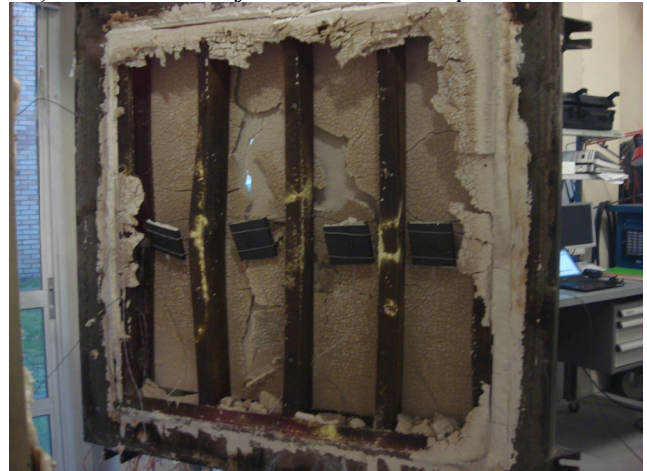

d) Final state of the LSF wall specimen 02.

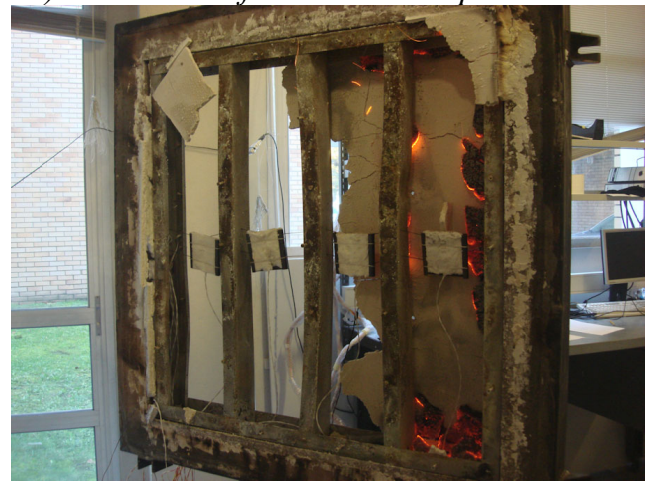

h) Final state of the LSF wall specimen 04. 


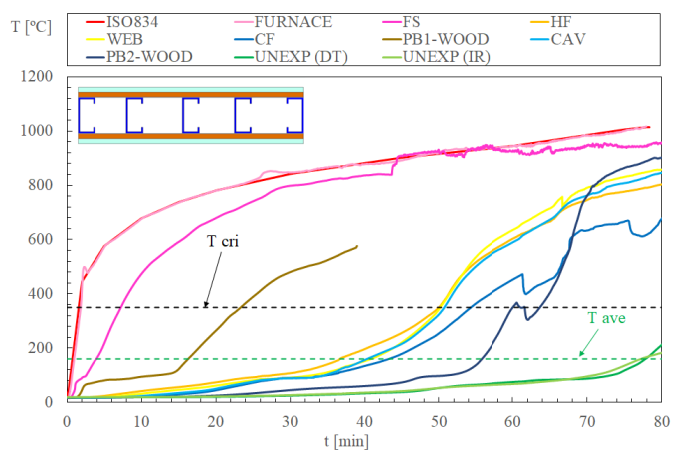

i) average temperature results for specimen 07 .

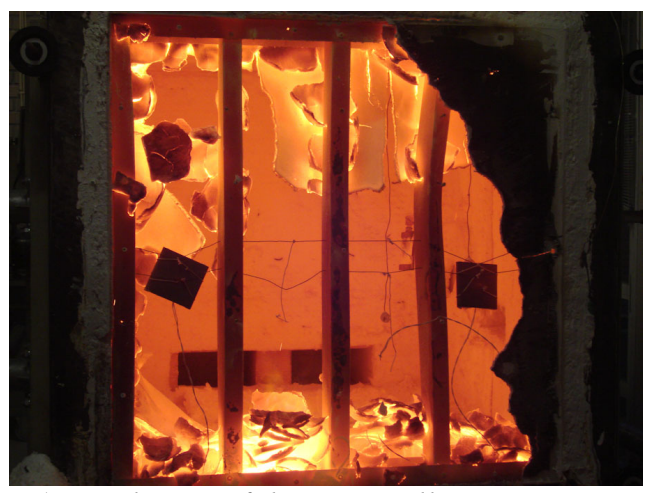

j) Final state of the LSF wall specimen 07.

Figure 3:Temperature history and limit state for the specimens

The temperature over the unexposed surface was monitored and allows to determine the fire resistance time, used for fire rating (I). The critical time was determined for every specimen, taking into consideration all the possible criteria and measuring methods. The traditional and standard method, used disk thermocouples (DT) and allowed for the maximum temperature and average temperature measurement. The infrared thermal camera method allowed for the calculation of the average temperature (IR) in a wide predefined area. Both measurement methods agree very well with respect to the definition of the fire resistance, see Table 2.

Table 2:Fire resistance for insulation criteria.

\begin{tabular}{|l|l|l|l|}
\hline Specimen ID & $\begin{array}{l}\text { T } \mathbf{m a x}=\mathbf{2 0 0}(\mathbf{D T}) \\
{[\mathbf{m i n}]}\end{array}$ & $\begin{array}{l}\text { T ave=160 (DT) } \\
{[\mathbf{m i n}]}\end{array}$ & $\begin{array}{l}\text { T ave=160 (IR) } \\
{[\mathbf{m i n}]}\end{array}$ \\
\hline 01 & 70 & 71 & 62 \\
\hline 02 & 119 & 118 & 117 \\
\hline 04 & 55 & 51 & 50 \\
\hline 07 & 77 & 75 & 77 \\
\hline
\end{tabular}




\section{Numerical analysis}

The numerical model uses the thermal and the structural analysis, representative of the fire effect, duly validated, to allow for the determination of the loadbearing capacity of each wall type. The finite element model uses shell and solid finite elements with linear interpolating functions and full integration schemes from ANSYS. The simulation is divided in 4 steps.

In the first step, a three dimensional linear elastic stability model is defined to determine the critical load and the corresponding mode of instability. The boundary conditions are defined according to Figure 4, fixing the bottom surface of the wall (web of the bottom track) and restraining some screw positions in the parallel direction to the base of the wall (direction $\mathrm{X}$ ). The web of the upper track was modelled with a bigger thickness to simulate the interface beam, normally used on experimental tests to distribute the load over the top surface of the wall. The interface will be responsible for the distribution of 3 vertical forces (FZ) applied on the top surface of the top track and coincident with the direction of the three central vertical studs. The Block Lanczos method was used to extract the first modes of instability. In this case the first eigenvalue was selected, corresponding to a local instability mode (local buckling of the web). The maximum displacement value was also recorded for the definition of the scale factor used to update the geometric imperfections of the structure(Schafer \& Peköz, 1998).

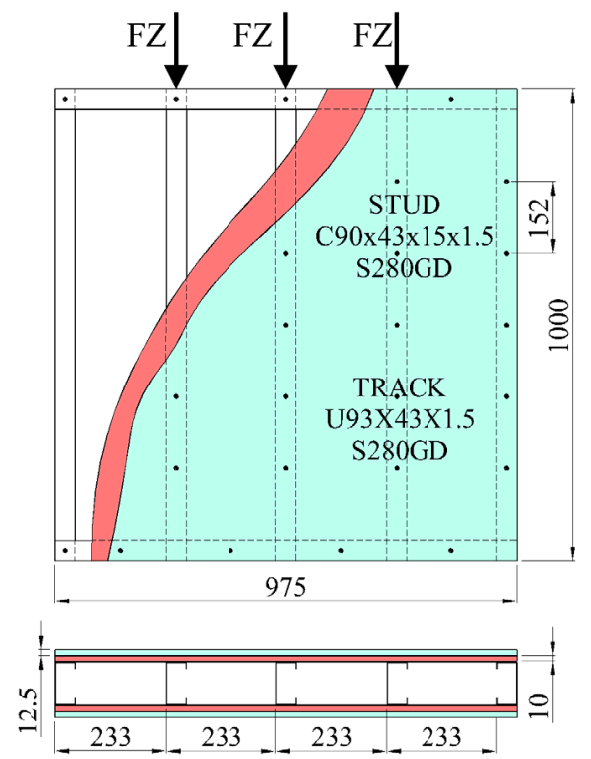

a) Loadbearing LSF wall specimen with composite panels.

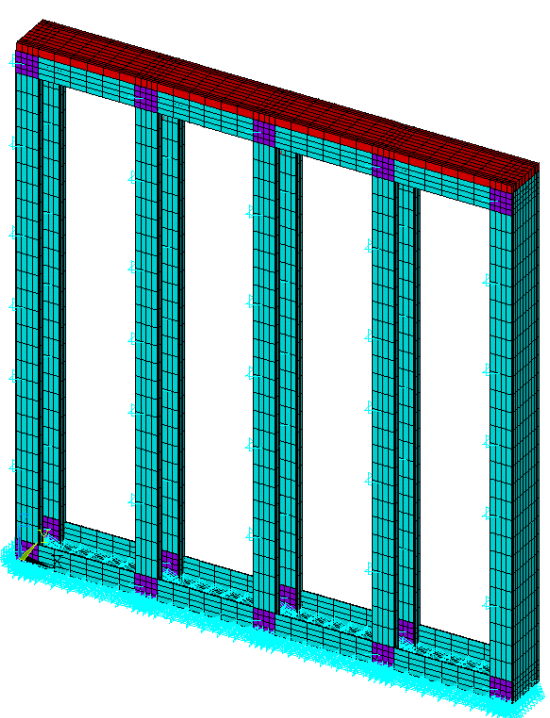

b) Finite element mesh and boundary conditions.

Figure 4: Loadbearing LSF wall. Geometry and finite element model 
In the second step, the geometry (position of the nodes) is updated, to include the geometric imperfection. The mechanical properties of cold formed steel at room temperature are also defined for room temperature, see Figure 5. The LSF is the only material to be considered for the loadbearing capacity of the wall. All other materials, that may contribute to the strength and collapse mode of the structure (Petrone, Magliulo, \& Manfredi, 2016), will not be considered for the calculation of the loadbearing capacity. An incremental and iterative solution method was applied to determine the loadbearing capacity. The arc-length method was used with a maximum load increment of $800 \mathrm{~N}$ and with a minimum load increment of $8 \mathrm{~N}$, applied at each of the 3 load points (FZ). The convergence criterion for the solution was defined for displacement with a zero reference value and with a tolerance of $5 \%$. This solution method allows to determine the potential mode of collapse of the wall structure and its loadbearing capacity.

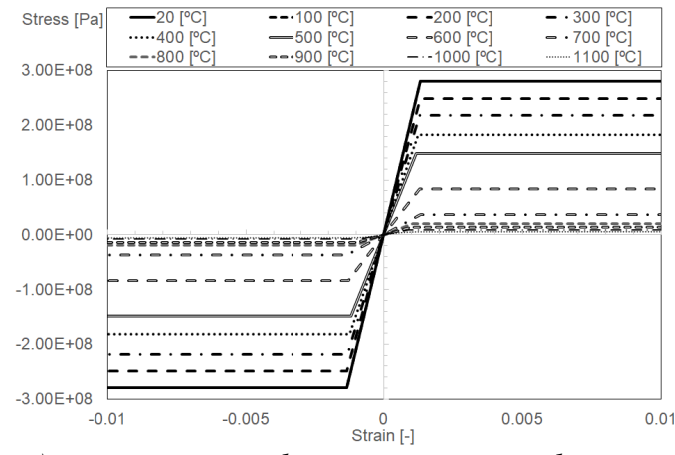

a) stress strain under compression and tension

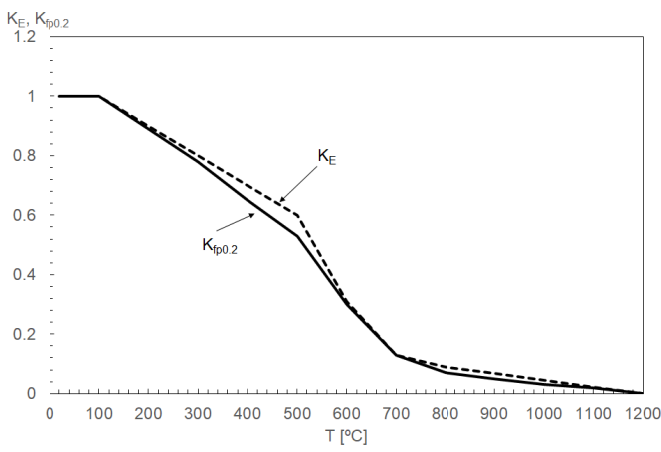

b) reduction coefficients for the elastic modulus and $0.2 \%$ proof strength

Figure 5: Mechanical properties of cold formed steel at room and elevated temperature

This results allow to define the maximum loadbearing capacity of the wall. This structure is capable of supporting a maximum point load of $\mathrm{FZ}=78612 \mathrm{~N}$, at room temperature. The deformed mode shape confirms the existence of local buckling mode of the web for the central stud and also a distortional buckling mode in the upper part of the other studs. The yield stress of the material was reached in some parts of the LSF structure.

The thermal part model of the wall is validated in the third step. Finite elements of multilayer shell were used to model the LSF and solid finite elements were used to represent the plate layers. The appropriate boundary conditions were used according to each test and according to the document on actions in structures submitted to standard fire EN1991-1-2 (CEN- European Committee for Standardization, 2002). For all the finite element models, boundary conditions of convection and radiation were included inside the empty cavity. The bulk temperature in the cavity region is determined by the average value of the measurements made by the plate 
thermocouples, from TP1 to TP4. In this way and with high accuracy, the effect of the cracks or other type of failure of the plasterboards is considered, including also the effect of the ignition and heat release rate of the combustible material. The other common boundary conditions were applied to the exposed side and unexposed side. Heat flow by convection was considered in the exposed surface using a heat transfer coefficient of $25 \mathrm{~W} / \mathrm{m}^{2} \mathrm{~K}$ and the heat flow by radiation with an emissivity of the flames equal to 1 . In both cases the temperature inside the furnace was considered to rise according to the ISO834. On the unexposed surface, only the convective heat flow was considered, with a heat transfer coefficient of $9 \mathrm{~W} / \mathrm{m}^{2} \mathrm{~K}$ to include the effect of radiation. The temperature outside the furnace was considered equal to the initial mean temperature $\left(20^{\circ} \mathrm{C}\right)$. In the internal region of the cavity, the conditions of heat flow by convection and radiation were considered, assuming a heat transfer coefficient of $17.5 \mathrm{~W} / \mathrm{m}^{2} \mathrm{~K}$ and a flame emissivity value of 1 . The cavity temperature was determined according to the average value of the measurements made by the plate thermocouples TP1 to TP4. The thermal properties of the materials were considered temperature dependent, see Figure 6. The thermal properties of the cork were assumed as closed as possible to the variation of the thermal properties of the wood with the temperature using data from EN1995-1-2 (CEN- European Committee for Standardization, 2004), but duly adjusted with the values determined at room temperature by the hot disk method (International Organization for Standardization, 2015). The variation of the thermal properties for the steel were assumed in accordance to Eurocode EN1993-1-2 (CEN- European Committee for Standardization, 2005). The thermal properties of the gypsum were considered from Mohamed A. Sultan (Sultan, 1996).

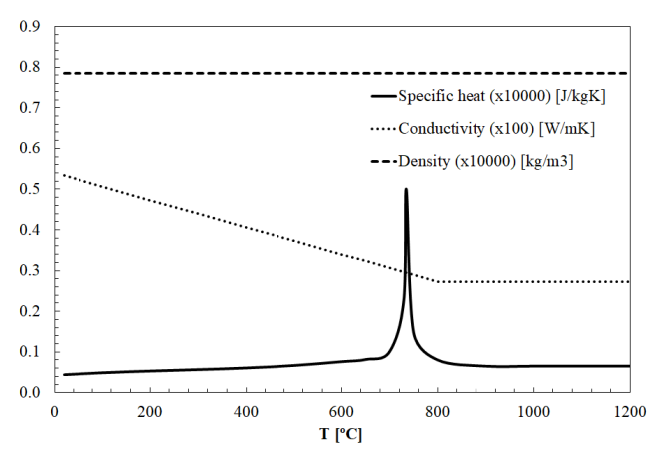

a) steel

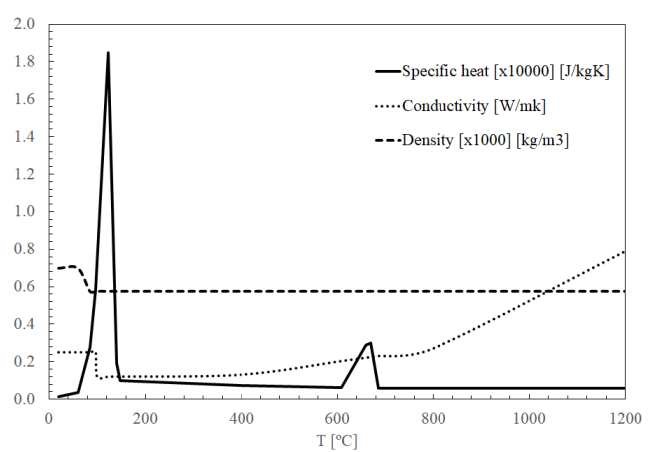

b) gypsum 


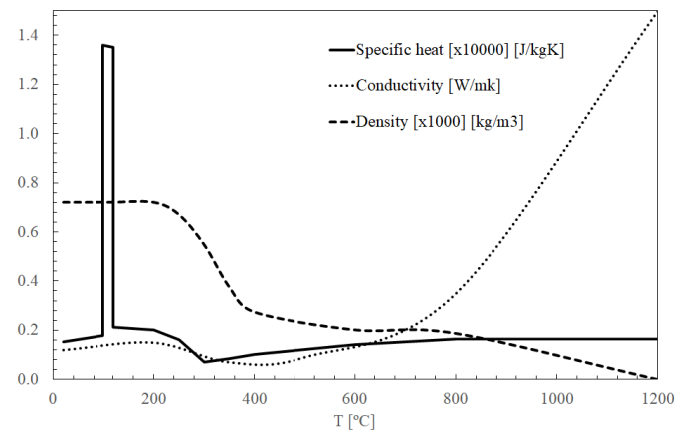

c) Wood

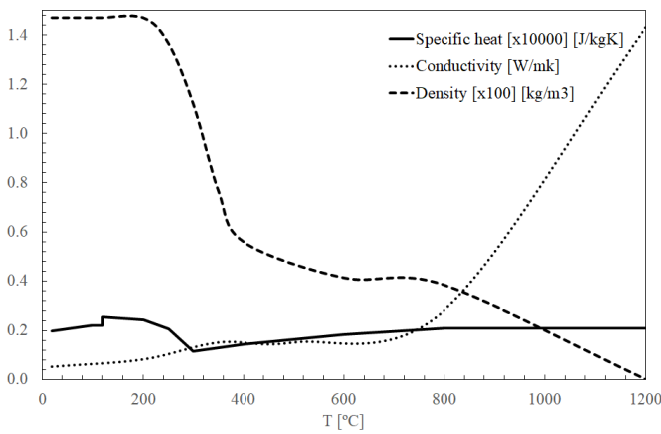

d) cork

Figure 6: Thermal properties for all the materials involved in heat flow analysis

The thermal solution was considered transient and nonlinear, using an incremental procedure with a time step of $60 \mathrm{~s}$, with the possibility to be reduce to $1 \mathrm{~s}$. Figure 7 shows the temperature field for the critical time of the complete model of the wall and for the LSF structure.

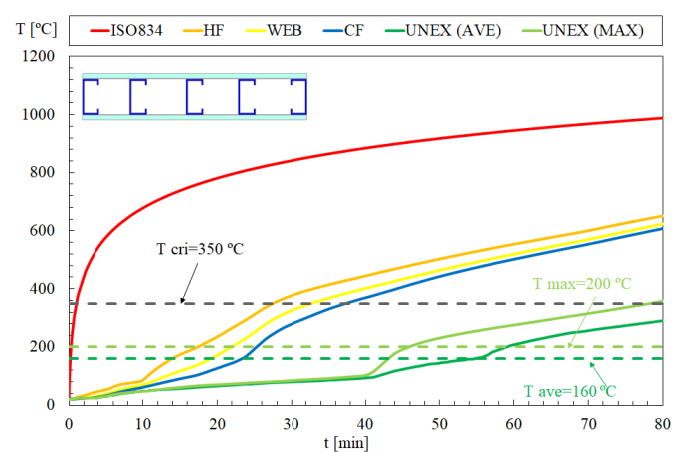

a) Time temperature history for specimen 01 .

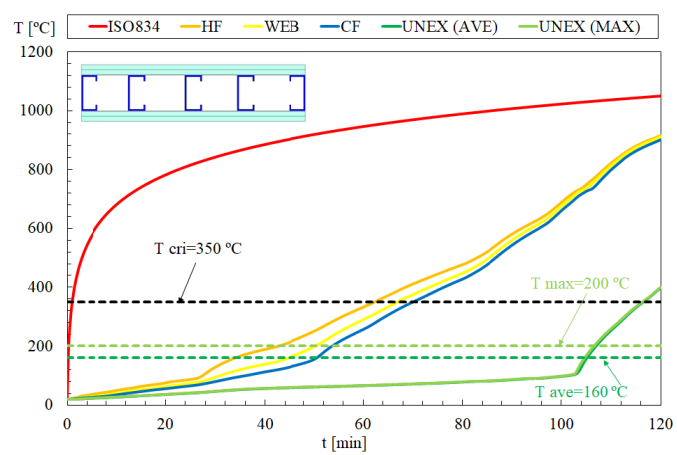

c) Time temperature history for specimen 02.

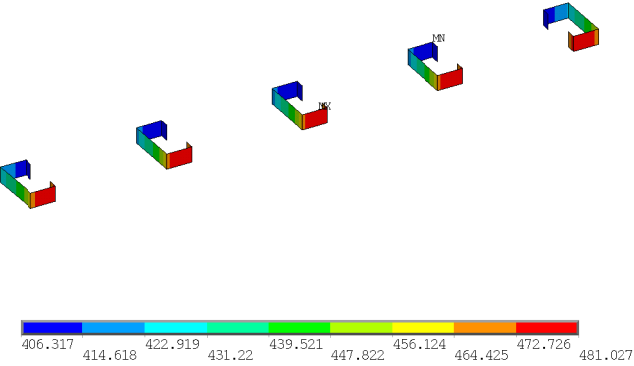

b) Temperature in the LSF, at half height, for the critical time of 45 min.

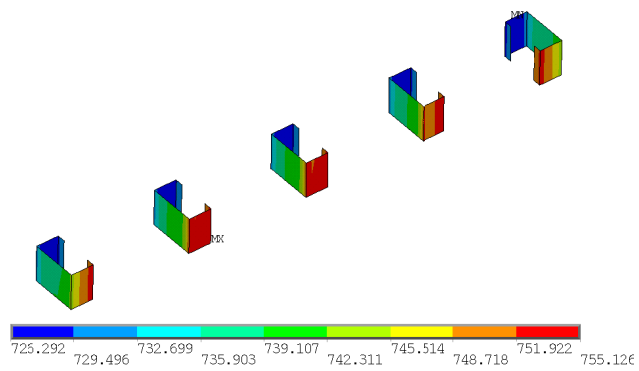

d) Temperature in the LSF, at half height, for the critical time of $105 \mathrm{~min}$ 


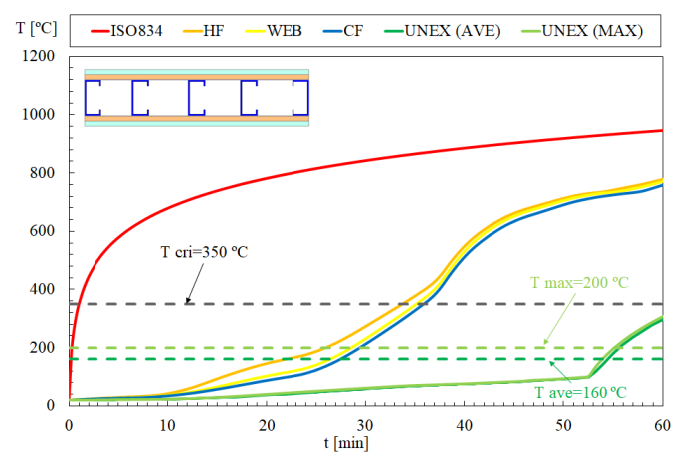

e) Time temperature history for specimen 04 .

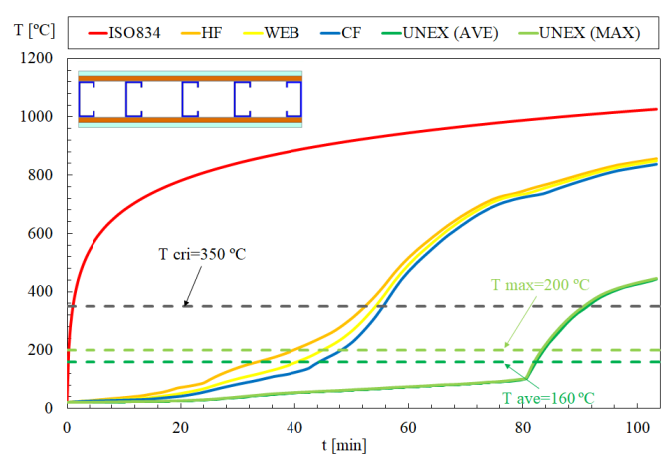

g) Time temperature history for specimen 07.

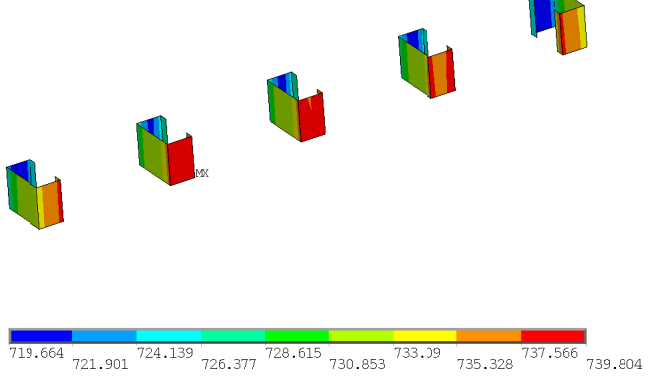

f) Temperature in the LSF, at half height, for the critical time of 54 min.

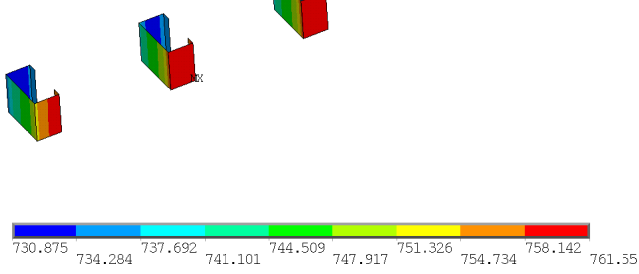

h) Temperature in the LSF, at half height, for the critical time of $82 \mathrm{~min}$.

Figure 7: Numerical results for the thermal analysis for all the specimens

Table 3 presents a comparison between the numerical and experimental results. The difference between the results determined for the fire resistance are in between $9.7 \%$ and $35 \%$. The comparison was made between the criteria applied for DT, using the smallest time to reach each condition, in completed minutes. 
Table 3:Fire resistance determined using the insulation criteria

\begin{tabular}{|l|l|l|l|l|l|}
\hline Specimen & $\begin{array}{l}\text { T } \mathbf{m a x}=\mathbf{2 0 0} \\
(\mathbf{D T}) \\
{[\mathbf{m i n}]}\end{array}$ & $\begin{array}{l}\text { T ave=160 } \\
(\mathbf{D T}) \\
{[\mathbf{m i n}]}\end{array}$ & $\begin{array}{l}\text { T ave=160 } \\
(\mathbf{I R}) \\
{[\mathbf{m i n}]}\end{array}$ & $\begin{array}{l}\text { T } \mathbf{m a x}=\mathbf{2 0 0} \\
(\mathbf{D T}) \\
{[\mathbf{m i n}]}\end{array}$ & $\begin{array}{l}\text { T ave=160 } \\
\text { (DT) } \\
\text { [min] }\end{array}$ \\
\hline ID & Experimental & Experimental & Experimental & Numerical & Numerical \\
\hline 01 & 70 & 71 & 62 & 54 & 45 \\
\hline 02 & 119 & 118 & 117 & 105 & 106 \\
\hline 04 & 55 & 51 & 50 & 54 & 55 \\
\hline 07 & 77 & 75 & 77 & 82 & 83 \\
\hline
\end{tabular}

In the fourth step, an estimate of the fire resistance $(\mathrm{R})$ is presented for different load levels, corresponding to different degrees of utilization, variable between 40 and $80 \%$, see Table 4. This load level is calculated with respect to the maximum loadbearing capacity of the LSF structure at room temperature $(\mathrm{FZ}=78612 \mathrm{~N})$. The model uses an incremental and iterative static analysis, based on a nonlinear and geometric material model. The time step is equal to $60 \mathrm{~s}$ with the possibility to be reduced to $0.1 \mathrm{~s}$. The Newton Raphson method uses a displacement-based convergence criterion with a zero reference value and a tolerance of 5\%. This step forces a modification of finite shell element, while solid elements are removed from the model. The restraints for the displacements are exactly the same as those considered in the previous structural step (first and second step). It is assumed that gypsum, cork and OSB boards do not contribute to the calculation of the mechanical loadbearing capacity, but these materials are considered during the thermal effect of the fire. A perfectly elastic-plastic material behaviour model is also assumed at elevated temperature, see Figure 5, according to EN1993-1-5 (CENEuropean Committee for Standardization, 2006). 
Table 4:Fire Resistance Determined using the Insulation Criteria

\begin{tabular}{|l|l|l|l|l|l|}
\hline $\begin{array}{l}\text { Specimen } \\
\text { ID }\end{array}$ & $\begin{array}{l}\text { Load } \\
\text { level } \\
{[\%]}\end{array}$ & $\begin{array}{l}\text { Steel } \text { min. } \\
\text { temperature }\left[{ }^{\mathbf{0}} \mathbf{C}\right]\end{array}$ & $\begin{array}{l}\text { Steel max. } \\
\text { temperature }\left[{ }^{\mathbf{}} \mathbf{C}\right]\end{array}$ & $\begin{array}{l}\text { Steel average } \\
\left.\text { temperature }{ }^{\mathbf{0}} \mathbf{C}\right]\end{array}$ & $\begin{array}{l}\text { Fire } \\
\text { resistance } \\
(\mathbf{R})[\mathbf{m i n}]\end{array}$ \\
\hline 01 & 40 & 527 & 584 & 556 & 65 \\
\hline & 50 & 484 & 548 & 516 & 57 \\
\hline & 60 & 412 & 491 & 452 & 46 \\
\hline & 70 & 307 & 414 & 361 & 34 \\
\hline & 80 & 199 & 341 & 270 & 25 \\
\hline 02 & 40 & 536 & 592 & 564 & 90 \\
\hline & 50 & 485 & 547 & 516 & 86 \\
\hline & 60 & 429 & 495 & 462 & 81 \\
\hline & 70 & 334 & 414 & 374 & 69 \\
\hline & 80 & 251 & 344 & 298 & 60 \\
\hline 04 & 40 & 513 & 612 & 563 & 41 \\
\hline & 50 & 445 & 557 & 501 & 39 \\
\hline & 60 & 406 & 519 & 463 & 38 \\
\hline & 70 & 333 & 433 & 383 & 36 \\
\hline & 80 & 238 & 341 & 290 & 32 \\
\hline 07 & 40 & 506 & 588 & 547 & 63 \\
\hline & 50 & 467 & 556 & 512 & 61 \\
\hline & 60 & 423 & 522 & 473 & 59 \\
\hline & 70 & 324 & 434 & 379 & 52 \\
\hline & 80 & 258 & 367 & 313 & 52 \\
\hline
\end{tabular}

Results include the time in complete minutes and the critical temperature for the LSF structure. Local buckling of the web and distortional buckling are the potential failure modes for this type of LSF walls. The fire resistance decreases with the increase of the load level, see Figure 8. The average critical temperature of all the specimens is approximately the same for each load level.

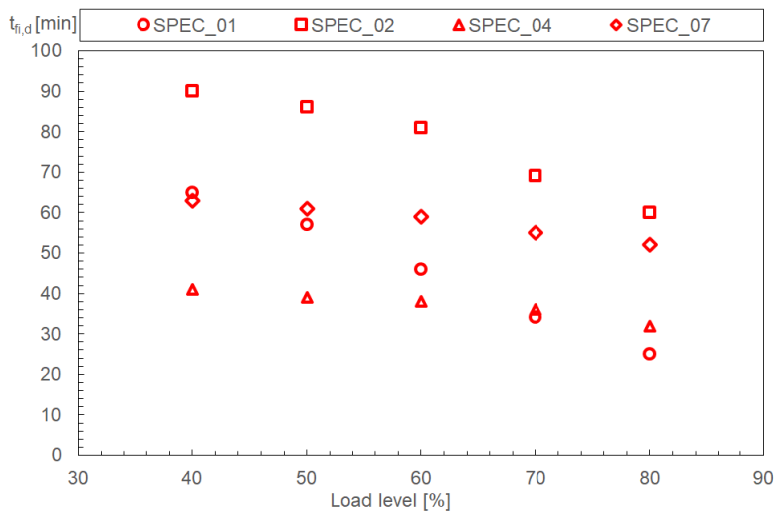

a) Fire resistance for all the specimens.

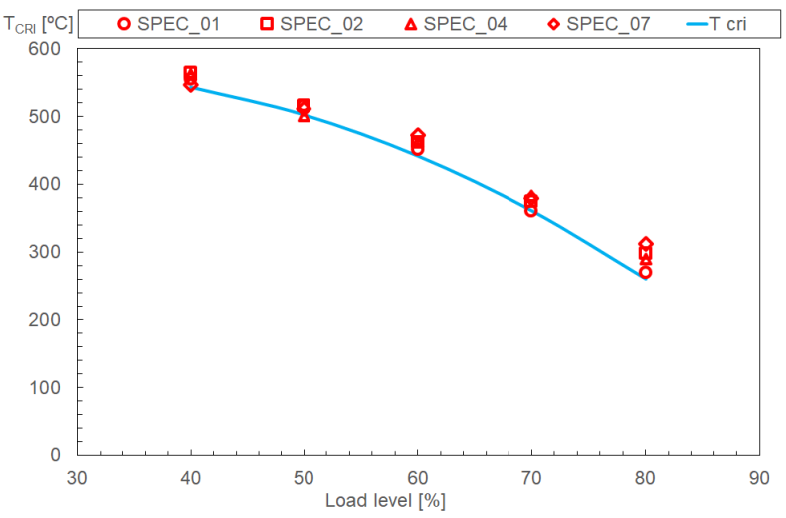

b) Critical temperature of the LSF structure (average).

Figure 8: Fire resistance and average critical temperature for all simulated specimens 
The fire resistance depends on the load level $\mu$ and the critical temperature can be approximated by Eq. 1, for this type of LSF frame structure and for all the composite layer solutions presented herein.

$$
T_{\text {CRI }}=-0.0997 \times \mu^{2}+4.0935 \times \mu+506.35
$$

This critical temperature demonstrates that the simple calculation method presented in Eurocode EN1993-1-2 (CEN- European Committee for Standardization, 2005), which states that the fire resistance could be verified, for a specific time, when the temperature of the cross section is not more than $350{ }^{\circ} \mathrm{C}$, when applied to this type of elements (class 4 cross sections) is over conservative for the majority of the tested cases and unsafe for the case of the load level higher than $70 \%$.

\section{Conclusions}

This investigation presents a hybrid solution method to predict the fire resistance of loadbearing walls, after the development of experimental tests on partition walls with the same type of geometry. This solution method requires an extra temperature measurement for the evolution in the cavity and the selection of the appropriate heat flow coefficients. This measurement is of extreme importance to account for all the major events that occur during experimental tests (cracks and ignition of combustible materials).

The results of four experimental tests are presented. All specimens were made with the same LSF structure. Specimen 07 presents higher fire resistance when compared with specimen 04, demonstrating the worst fire performance of the composite solution using cork material in comparison with a composite solution using OSB. The LSF wall with double layer of gypsum almost reached the fire rating of 2 hours.

The numerical simulation model includes a four step solution method. The first step was developed with a linear elastic buckling analysis to find the critical load of the LSF structure and also the main instability mode shape. The first mode of instability is normally used to define the imperfection of the LSF structure. The second step of the numerical simulation allowed for the calculation of the loadbearing capacity of the LSF wall. The mechanical resistance of the gypsum, cork and OSB was neglected. The third stepof the numerical simulation used a nonlinear thermal analysis, with all materials included, to predict the thermal effect of the fire into 
the LSF structure. This analysis was validated with experimental results and allows for the fire rating (I) of the LSF wall structure. These results depend on the major events occurred during each experimental test (cracks, flaws of materials and connections, energy released after ignition of combustible materials) that were taken into account when using the boundary condition for radiation and convection, assuming the bulk temperature of the cavity equal to the measured (CAV). The fourth stepof the numerical simulation used a geometric and material non-linear analysis to predict the fire resistance of loadbearing walls made with the same materials as the ones tested without load. The fire resistance decreases with the increase of the load level and the average critical temperature of the steel structure is approximately the same for each load level. A new formula is proposed for the definition of the critical temperature.

Experimental tests are being prepared with load and fire, to validate the critical temperature of the LSF structure under different load levels.

\section{Acknowledgments}

Special thanks are due to the companies: Amorim Composites, FALPER / Fibroplac, F. Pereira building Materials and Normago.

\section{References}

Alfawakhiri, F., \& Sultan, M. A. (2000). Fire resistance of loadbearing LSF assemblies. In 15th International Specialty Conference on Cold- Formed Steel Structures (pp. 545-561). St. Louis, MO, U.S.A. Retrieved from http://www.scopus.com/inward/record.url?eid=2$\underline{\mathrm{s} 2.0-3042660153 \& \text { partnerID }=40 \& \mathrm{md} 5=\mathrm{c} 0 \mathrm{c} 10 \mathrm{ef} 1 \mathrm{~d} 600 \mathrm{f} 8 \mathrm{e} 6810705 \mathrm{e} 9 \mathrm{bc} 895 \mathrm{af} 7}$

Alfawakhiri, F., Sultan, M. A., \& MacKinnon, D. H. (1999). Fire resistance of loadbearing steelstud walls protected with gypsum board: A review. Fire Technology, 35(4), 308-335. https://doi.org/10.1023/A:1015401029995

CEN- European Committee for Standardization. (2002). EN 1991-1-2, Eurocode 1: Actions on structures - Part 1-2: General actions - Actions on structures exposed to fire. (CENEuropean Committee for Standardization, Ed.), CEN- European Committee for Standardization. Brussels: CEN- European Committee for Standardization.

CEN- European Committee for Standardization. (2004). EN 1995-1-2 : Eurocode 5 - Design of timber structures Part 1-2: General - Structural fire design. (CEN- European 
Committee for Standardization, Ed.), CEN- European Committee for Standardization (CEN-Europ). CEN- European Committee for Standardization.

CEN- European Committee for Standardization. (2005). EN 1993-1-2: European StandardEurocode 3: Design of steel structures - Part 1-2: General rules - Structural fire design. (CEN- European Committee for Standardization, Ed.) (CEN-Europ). Brussels: CEN- European Committee for Standardization.

CEN- European Committee for Standardization. (2006). EN 1993-1-5: Eurocode 3 - Design of steel structures - Part 1-5: Plated structural elements. (CEN- European Committee for Standardization, Ed.), CEN- European Committee for Standardization (CEN-Europ). Brussels: CEN- European Committee for Standardization.

CEN- European Committee for Standardization. (2012). EN 1363-1: Fire resistance tests Part 1 : General Requirements. (CEN- European Committee for Standardization, Ed.) (CENEurop). Brussels: CEN- European Committee for Standardization.

CEN- European Committee for Standardization (Ed.). (2015). EN 1364-1: Fire resistance tests for non-loadbearing elements. Part 1: Walls (CEN). Brussels: CEN.

Gerlich, J. T., Collier, P. C. R., \& Buchanan, A. H. (1996). Design of light steel-framed walls for fire resistance. Fire and Materials, 20(2), 79-96. https://doi.org/10.1002/(SICI)10991018(199603)20:2<79::AID-FAM566>3.0.CO;2-N

Gerlich, J. T. H. (1995). Design of Loadbearing Light Steel Frame Walls for Fire Resistance. Fire Engineering Research Report 95/3, 118. https://doi.org/ISSN 1173-5996

International Organization for Standardization. (1999). ISO834-1: Fire-resistance tests Elements of building construction - Part 1: General requirements. (International Organization for Standardization, Ed.) (Internatio). International Organization for Standardization.

International Organization for Standardization. (2015). 22007-2: Plastics - Determination of thermal conductivity and thermal diffusivity - Part 2: Transient plane heat source (hot disc) method. (International Organization for Standardization, Ed.). International Organization for Standardization.

Keerthan, P., \& Mahendran, M. (2013). Thermal Performance of Composite Panels Under Fire Conditions Using Numerical Studies: Plasterboards, Rockwool, Glass Fibre and Cellulose Insulations. Fire Technology, 49(2), 329-356. https://doi.org/10.1007/s10694$\underline{012-0269-6}$ 
Kesawan, S., \& Mahendran, M. (2015). Fire tests of load-bearing LSF walls made of hollow flange channel sections. Journal of Constructional Steel Research, 115, 191-205. https://doi.org/10.1016/j.jcsr.2015.07.020

Kesawan, S., \& Mahendran, M. (2017). Fire Performance of LSF Walls made of Hollow Flange Channel Studs Sivakumar. Journal of Structural Fire Engineering, 8(2), 149-180. https://doi.org/10.1108/JSFE-03-2017-0027

Khetata, M., Fernandes, L., Marinho, C., Piloto, P., Gavilán, A., \& Razuk., H. (2017). Fire resistance of non-loadbearing light steelframing walls: numerical validation. In $X I$ Portuguese Congress on Steel and Composite Construction - CMM 2017 (pp. 853-862). Coimbra, Potugal: Portuguese Association for Steel and Composite Construction.

Kolarkar, P. N. (2010). Structural and Thermal Performance of Cold-formed Steel Stud Wall Systems under Fire Conditions. Queensland University of Technology.

Petrone, C., Magliulo, G., \& Manfredi, G. (2016). Mechanical properties of plasterboards: experimental tests and statistical analysis. Journal of Materials in Civil Engineering, 28(11), 1-12. https://doi.org/10.1061/(ASCE)MT.1943-5533.0001630

Piloto, P. A. G. (2018). Fire resistance of cold-formed steel walls with composite panels : Results from insulation rating ( I ) and loadbearing prediction rating ( R ). Metálica International, (7), 12-17.https://doi.org/10.30779/cmm_metalica_mi07_02

Piloto, P. A. G., Khetata, M. S., \& Gavilán., A. B. R. (2017). Fire performance of nonloadbearing light steel framing walls - numerical simulation. In 7th international conference mechanics and materials in design (pp. 1603-1610). Albufeira, Portugal: INEGI/FEUP.

Piloto, P. A. G., Khetata, M. S., \& Gavilán, A. B. R. (2017). Fire Performance of NonLoadbearing Light Steel Framing Walls-Numerical and simple calculation methods. MATTER: International Journal of Science and Technology, 3(3), 13-23. https://doi.org/10.20319/mijst.2017.33.1323

Sakumoto, Y., Hirakawa, T., Masuda, H., \& Nakamura, K. (2003). Fire Resistance of Walls and Floors Using Light-Gauge Steel Shapes. Journal of Structural Engineering, 129(November), 1522-1530. https://doi.org/10.1061/(ASCE)07339445(2003)129:11(1522)

Schafer, B. W., \& Peköz, T. (1998). Computational modeling of cold-formed steel: characterizing geometric imperfections and residual stresses. Journal of Constructional 
Steel Research, 47(3), 193-210. https://doi.org/10.1016/S0143-974X(98)00007-8

Schwartz, K. J., \& Lie, T. T. (1985). Investigating the unexposed surface temperature criteria of standard ASTM E119. Fire Technology, 21(3), 169-180. https://doi.org/10.1007/BF01039972

Shahbazian, A., \& Wang, Y. C. (2013). A simplified approach for calculating temperatures in axially loaded cold-formed thin-walled steel studs in wall panel assemblies exposed to fire from one side. Thin-Walled Structures, 64, 60-72.

https://doi.org/10.1016/j.tws.2012.12.005

Sivakumar Kesawan and Mahen Mahendran. (2016). Thermal performance of load-bearing walls made of cold-formed hollow flange channel sections in fire. Fire and Materials, 40(5), 704-730. https://doi.org/10.1002/fam.2337

Son, B. C., \& Shoub, H. (1973). Fire Endurance Tests of Double Module Walls of Gypsum Board and Steel Studs. Washington, D.C. 202234.https://doi.org/10.6028/NBS.IR.73-173

Sultan, M. A. (1996). A model for predicting heat transfer through noninsulated unloaded steelstud gypsum board wall assemblies exposed to fire. Fire Technology, 32(3), 239-259. https://doi.org/10.1007/BF01040217 